\title{
Congenital Diaphragmatic Hernia in a Fetus with a De novo Terminal Deletion of Chromosome 15q26.1
}

\section{Ruth $\mathrm{C}^{1 *}$, Starcevic $\mathrm{J}^{2}$, Bartholomew $\mathrm{ML}^{3}$, Qin $\mathrm{N}^{4}$ and Slavin TP ${ }^{2,5}$}

${ }^{1}$ Fetal Diagnostic Center, Kapiolani Medical Center for Women and Children

${ }^{2}$ Department of Pediatrics, University of Hawaii, John A. Burns School of Medicine

${ }^{3}$ Department of Obstetrics and Gynecology, Division of Maternal Fetal Medicine, University of Hawai'i, John A. Burns School of Medicine

${ }^{4}$ Genzyme Genetics, Orange, California

${ }^{5}$ Kapiolani Medical Specialists, Honolulu, Hawaii

\begin{abstract}
De novo terminal deletions of chromosome 15q26.1 are rare occurrences. Deletions of this region have been previously linked to congenital diaphragmatic hernia $(\mathrm{CDH})$ as well as congenital malformations and developmental delay. This article presents a prenatal case of this de novo terminal deletion, detected by cytogenetic analysis and confirmed by fluorescence in situ hybridization (FISH), in a fetus with $\mathrm{CDH}$ and intrauterine growth restriction (IUGR). Genetic evaluation of pre- and postnatal cases of $\mathrm{CDH}$ should include at least a close examination of the terminal region of chromosome 15q26. As with any de novo substantial loss of genetic material, the prognosis is likely to include additional neurologic impairment and other congenital malformations in comparison to $\mathrm{CDH}$ patients without genomic alterations.
\end{abstract}

Keywords: Congenital diaphragmatic hernia; Prenatal diagnosis; 15q deletion; Chromosomal deletion

\section{Introduction}

De novo terminal deletions of chromosome 15q26.1 are rare events and/or seldom diagnosed. Likewise, few are reported in the literature. We present a prenatal case of a de novo terminal deletion of one copy of chromosome 15 in a fetus with $\mathrm{CDH}$. This case report describes the defined deleted region and discusses its association with $\mathrm{CDH}$, while presenting further support for the role of molecular genetic testing in fetuses and infants with $\mathrm{CDH}$.

\section{Case Report}

A 20-year-old gravida 2, para 1 mother and her 30-year-old husband were referred to our fetal diagnostic center at 11 weeks 4 days gestation for first trimester nuchal translucency (NT) screening. The initial ultrasound was significant for a NT measurement of $4 \mathrm{~mm}$. Given the increased NT thickness, the couple was counseled about the option of chorionic villus sampling (CVS) to detect a possible fetal chromosomal abnormality. They consented to the CVS procedure, and cytogenetic analysis revealed an abnormal male karyotype with a terminal deletion of the long arm of one copy of chromosome 15 (Figure 1). Fluorescence in situ hybridization studies using a whole chromosome paint probe for chromosome 15 and a subtelomere probe for the long arm of chromosome 15 (Vysis, Inc.) confirmed the terminal deletion (Figure 2). Parental chromosome analyses were normal for the nonconsanguineous couple. Therefore, the deletion in the fetus was de novo in origin: 46,XY,del(15)(q26.1)dn.ish del(15)(wcp+, D15S396-).

The couple returned to our fetal diagnostic center at 17 weeks 0 days gestation for a fetal anatomy survey by ultrasound, which showed intrauterine growth restriction (IUGR) and a left-sided CDH (Figure $3)$. Fetal head circumference was $131.6 \mathrm{~mm}$ ( $18^{\text {th }}$ percentile), abdominal circumference was $91.9 \mathrm{~mm}\left(<3^{\text {rd }}\right.$ percentile) and femur length was $20.6 \mathrm{~mm}\left(<3^{\text {rd }}\right.$ percentile). The stomach appeared in the chest, and the heart was displaced to the right. The lung to head ratio was 2.1. There was no liver herniation into the chest.

The family was counseled on the combined abnormal findings of the fetal karyotype, $\mathrm{CDH}$, and early IUGR. Termination of the pregnancy was elected at 18 weeks 2 days gestation. Fetopsy was declined by the family.

\section{Discussion}

Congenital diaphragmatic hernia, a severe birth defect involving
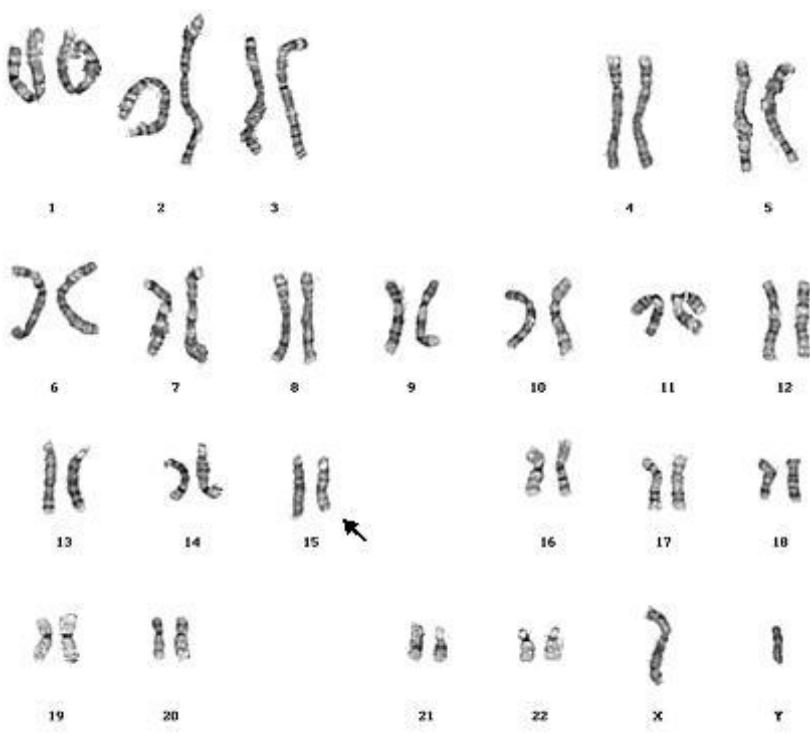

Figure 1: Cytogenic analysis revealing one normal copy of chromosome 15 and a terminal deletion of the long arm of the other copy of chromosome 15 (arrow).

*Corresponding author: Ruth, Chelsey 1319 Punahou Street, Suite 540 Honolulu, HI 96826; 808-983-6470; Fax: 808-983-8989; E-mail: chelsey.ruth@ kapiolani.org

Received November 05, 2011; Accepted December 12, 2011; Published december 16, 2011

Citation: Ruth C, Starcevic J, Bartholomew ML, Qin N, Slavin TP (2012) Congenital Diaphragmatic Hernia in a Fetus with a De novo Terminal Deletion of Chromosome 15q26.1. Hereditary Genetics 1:101. doi:10.4172/2161-1041.1000101

Copyright: ( 2012 Ruth C, et al. This is an open-access article distributed under the terms of the Creative Commons Attribution License, which permits unrestricted use, distribution, and reproduction in any medium, provided the original author and source are credited. 

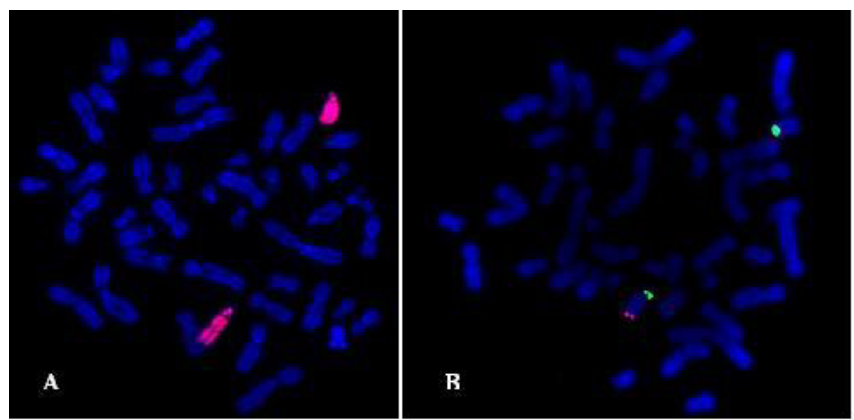

Figure 2: Fluorescence in situ hybridization studies using a whole chromosome paint probe for chromosome $15(\mathrm{~A})$ and a subtelomere probe for the long arm of chromosome 15 (B) (Vysis, Inc). There is one subtelomeric signal on the long arm of one copy of chromosome 15, indicating a terminal deletion on the other copy of chromosome 15.

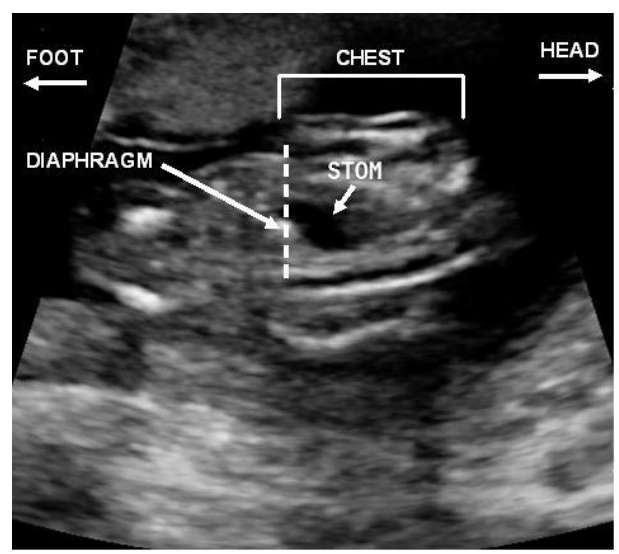

Figure 3: Sagittal ultrasound image of the fetal chest and abdomen revealing congenital diaphragmatic hernia at 17 weeks gestation. The stomach (STOM) appears in the chest consistent with $\mathrm{CDH}$.

incomplete or abnormal diaphragmatic closure, is frequently associated with life-threatening pulmonary hypoplasia and postnatal pulmonary hypertension. Half of the cases present with other nonpulmonary congenital anomalies and at least $5-10 \%$ of cases have a specific underlying chromosomal etiology [1].

Biggio et al. [2] presented a patient with a 46,XX,del(15)(q26.1) karyotype who was born with a $\mathrm{CDH}$, coarctation of the aorta, and dysmorphic features. They hypothesized that MEF2A, a myocytespecific enhancer factor, which maps to $15 \mathrm{q} 26$, may play a crucial role in the control of muscle differentiation and development of the diaphragm [2].

Slavotinek et al. [3] screened patients with $\mathrm{CDH}$ and additional phenotypic characteristics of Fryns syndrome. They used array comparative genomic hybridization (CGH) to identify more occult chromosomal aberrations. Results showed submicroscopic chromosome deletions in three probands who had normal karyotypes and were previously diagnosed with Fryns syndrome. Two of the three probands were found to have microdeletions in 15q26.6 while the other had a deletion in 8p23.1 [3]. Furthermore, You et al. [4] observed dorsolateral Bochdalek-type congenital diaphragmatic hernias in mice with NR2F2 gene deletions, and therefore, suggested that NR2F2 is a likely contributor to the formation of $\mathrm{CDH}$ in patients with $15 \mathrm{q}$ deletions.
Klaassens et al. [5] reported a patient with $\mathrm{CDH}$ with an approximately $5-\mathrm{Mb}$ deletion at $15 \mathrm{q} 26.1-26.2$. This region contained four known genes of which two, NR2F2 and CHD2, were particularly interesting candidates for CDH. Likewise, Lopez et al. [6] reported two cases of $\mathrm{CDH}$ and congenital heart disease, with one patient having a 15q26.1 deletion confirmed by FISH and array CGH [6].

Klaassens et al. [1] described two patients with a deletion of $15 \mathrm{q} 26$ with a common phenotype of IUGR, CDH, cardiac anomalies, and characteristic facial features similar to those seen in Fryns syndrome. They believed that this constellation of birth defects warranted further investigation to evaluate for $15 \mathrm{q} 26$ deletions. Also, Jaillard et al.[7] presented a female patient with multiple congenital malformations, including $\mathrm{CDH}$ and a heart defect, who was detected to have a terminal 6.9- $\mathrm{Mb}$ deletion of chromosome $15 \mathrm{q}$ associated with a structurally abnormal chromosome X.

Clugston et al. [8] used rodent diaphragms to study the expression of CDH candidate genes from $15 \mathrm{q} 26$, as well as FOG2 and GATA4, two genes in other $\mathrm{CDH}$ critical regions at 8q22-q23 and 8p23.1, respectively [8]. They concluded that the $15 \mathrm{q} 26 \mathrm{critical}$ region contains a cluster of genes, such as MEF2A, NR2F2, and CHD2, that are expressed in rodent diaphragm development, thus supporting other reports that deletions in this region are associated with $\mathrm{CDH}$ [8].

In contrast, there are many other patients described in the literature with 15q26.1 deletions who do not have $\mathrm{CDH}$ but have variable phenotype presentations, including facial dysmorphisms, short neck, complex heart defects, developmental delay, failure to thrive/growth restriction, cholestatic liver disease, severe feeding issues, and kidney and spinal cord abnormalities [9-11]. Therefore, haploinsufficiency of this region does not show complete penetrance for $\mathrm{CDH}$.

The chromosomal region $15 \mathrm{q} 26.1$ has many genes and presumed genetic regulatory regions. As such, the list of candidates that may be involved with $\mathrm{CDH}$ is large. In this particular case, the deleted region consisted of up to 59 genes and/or known gene regulatory loci, including all of the genes previously mentioned in this article: $M E F 2 A$, $N R 2 F 2$, and CHD2. Unfortunately, array CGH was not available in our case to define the deleted region further. The terminal deletion in this case was visible by chromosome analysis, so it may be much larger than deletions in other reported patients.

While the fetus in this case showed CDH and IUGR, other malformations could not be observed given the early ultrasound examination and termination of pregnancy without autopsy. Therefore, we cannot compare and contrast the phenotypic findings with those previously reported in other patients with 15q26.1 deletions. However, this case supports this chromosomal region's association with $\mathrm{CDH}$. Furthermore, as seen in some of the above case reports, molecular methods and FISH studies helped narrow down the genes and/or regulatory regions that are likely involved with $\mathrm{CDH}$ from 15 q26 deletions.

Based on this case, as well as a review of the literature, we recommend paying close attention to the $15 \mathrm{q} 26$ region in prenatal cases with clinical findings of $\mathrm{CDH}$. Deletions of this region contain many genes and/or regulatory elements that, in addition to $\mathrm{CDH}$, would be expected to involve other congenital malformations and neurologic impairment. Such deletions may lead to an overall poorer prognosis than that of isolated cases of $\mathrm{CDH}$ without genomic alterations. 
Therefore, as some small deletions or rearrangements of this region can sometimes be missed by karyotype, molecular methods such as chromosomal microarray, could be considered first tier genetic testing for $\mathrm{CDH}$ as their results may change pre- and postnatal counseling as well as overall prognosis.

\section{References}

1. Klaassens M, Galjaard RJ, Scott DA, Bruggenwirth HT, van Opstal D, et al.(2007) Prenatal detection and outcome of congenital diaphragmatic hernia $(\mathrm{CDH})$ associated with deletion of chromosome 15q26: two patients and review of the literature. Am j med genet A 143: 2204-2212.

2. Biggio JR, Descartes MD, Carroll AJ, Holt RL (2004) Congenital diaphragmatic hernia: is $15 q 26.1-26.2$ a candidate locus? American journal of medical genetics Part A 126A:183-185.

3. Slavotinek A, Lee SS, Davis R, Shrit A, Leppig KA, et al. (2005) Fryns syndrome phenotype caused by chromosome microdeletions at $15 q 26.2$ and 8p23.1. J med genet 42: 730-736

4. You LR, Takamoto N, Yu CT, Tanaka T, Kodama T, et al. (2005) Mouse lacking COUP-TFII as an animal model of Bochdalek-type congenital diaphragmatic hernia. Proc Natl Acad Sci USA 102: 16351-16356.

5. Klaassens M, van Dooren M, Eussen HJ, Douben H, den Dekker AT, et al (2005) Congenital diaphragmatic hernia and chromosome 15q26: determination of a candidate region by use of fluorescent in situ hybridization and array-based comparative genomic hybridization. Am J Hum Genet 76: 877-882.
6. Lopez I, Bafalliu JA, Bernabe MC, Garcia F, Costa M, et al. (2006) Prenatal diagnosis of de novo deletions of 8 p23.1 or $15 q 26.1$ in two fetuses with diaphragmatic hernia and congenital heart defects. Prenatal diagnosis 26: 577 580

7. Jaillard S, Loget P, Lucas J, Dubourg C, Le Bouar G, et al. (2011) Terminal $6.9 \mathrm{Mb}$ deletion of chromosome $15 \mathrm{q}$, associated with a structurally abnorma $X$ chromosome in a patient with congenital diaphragmatic hernia and heart defect. European journal of medical genetics 54 :186-188.

8. Clugston RD, Zhang W, Greer JJ (2008) Gene expression in the developing diaphragm: significance for congenital diaphragmatic hernia, American journa of physiology Lung cellular and molecular physiology 294: L665-675.

9. Tonnies H, Schulze I, Hennies H, Neumann LM, Keitzer R, et al (2001) De novo terminal deletion of chromosome $15 q 26.1$ characterised by comparative genomic hybridisation and FISH with locus specific probes. Journal of medical genetics 38: 617-621.

10. Bhakta KY, Marlin SJ, Shen JJ, Fernandes CJ (2005) Terminal deletion of chromosome 15q26.1: case report and brief literature review. Journal of perinatology : official journal of the California Perinatal Association 25: 429-432.

11. Davidsson J, Collin A, Bjorkhem G, Soller M (2008) Array based characterization of a terminal deletion involving chromosome subband $15 \mathrm{q} 26.2$ an emerging syndrome associated with growth retardation, cardiac defects and developmental delay. BMC medical genetics 9: 2. 